\title{
Erratum to: Pentalogy of Cantrell and Sternal Cleft: a report of two cases and review of literature
}

\author{
Josephat Maduabuchi Chinawa ${ }^{1}$ - Vijay Agarwal ${ }^{2} \cdot$ Swati Garekar $^{2}$. \\ Sarang Gaikwad ${ }^{2} \cdot$ Bhadra Trivedi $^{2}$
}

Published online: 8 May 2017

(C) Indian Association of Cardiovascular-Thoracic Surgeons 2017

Erratum to: Indian J Thorac Cardiovasc Surg.

DOI 10.1007/s12055-017-0525-y

The published online version of the paper contains mistake on the article title. It was captured as "Cantrell and Sterna Cleft: a report of two cases and review of literature." instead of "Pentalogy of Cantrell and Sternal Cleft: a report of two cases and review of literature". The corrected title is shown above.

The online version of the original article can be found at http://dx.doi.org/ 10.1007/s12055-017-0525-y

Josephat Maduabuchi Chinawa

josephat.chinawa@unn.edu.ng

Vijay Agarwal

tanishq26@yahoo.com

Swati Garekar

swatigar@gmail.com

Sarang Gaikwad

sarangonline@yahoo.com

Bhadra Trivedi

bhadra81@gmail.com

1 College of Medicine, Department of Pediatrics, University of Nigeria/University of Nigeria Teaching Hospital (UNTH), Ituku-Ozalla, Enugu State, Nigeria

2 Fortis Hospital limited, Mulund Goregaon Link Road, Bhandup (West), Mumbai, India 